\title{
ANALISIS DAYA DUKUNG TIANG PANCANG DENGAN METODE ELEMEN HINGGA DAN SOFTWARE L-PILE
}

\author{
Yayat Hendrayana \\ Teknik Sipil, Fakultas Teknik, Universitas Majalengka \\ yayat_hendrayana@yahoo.go,id
}

\begin{abstract}
Abstarksi
Pada lokasi proyek telah dilakukan drilling dengan SPT beserta dengan tes-tes laboratorium geoteknik (Mekanika Tanah) untuk menginvestigasi perlapisan tanah, karakeristik tanah dan daya dukung tanah pada daerah proyek.Analisa tentang potensi likuifaksi adalah salah satu bagian terpenting yaitu karena dari struktur tanah yang dominan pasir dan lanau serta memiliki relative density atau konsistensi yang cenderung loose atau soft serta kemungkinan muka air tanah yang cukup tinggi. Kapasitas daya dukung ultimate $(Q u)$ dan allowable lateral( $H$ al)l telah dianalisa dengan metode Broms, metode Elemen Hingga (FEM) dan dengan bantuan program computer LPILE (Com624). Dari perhitungan-perhitungan diatas dapat disimpulkan : 1. Metode Broms : Kapasitas daya dukung lateral ultimate adalah 22.45 ton, $F K=3$ maka kapasitas lateral ijin adalah 7.5ton (Broms). 2. LPILE : Defleksi ijin pada kondisi 1/4 inch atau $0.64 \mathrm{~cm}$ maka beban lateral ijin statik adalah 3.5 ton dan untuk beban lateral ijin kondisi p-y cyclic adalah 6.5 ton.
\end{abstract}

Kata Kunci: Driling, Tanah; Pondasi, Ultimate,

\section{PENDAHULUAN}

Pada lokasi proyek telah dilakukan drilling dengan SPT beserta dengan tes-tes laboratorium geoteknik (Mekanika Tanah) untuk menginvestigasi perlapisan tanah, karakeristik tanah dan daya dukung tanah pada daerah proyek.

Terdapat juga tes PILE berupa PDA dan Kentledge untuk memverifikasi daya dukung aksial. Data-data diatas adalah bahan masukan sekaligus pertimbangan dalam menghitung dan merekayasa kapasitas daya dukung aksial dan lateral dari pondasi tiang pancang yang ada.

\section{PROFIL DAN KARAKTERISTIK PERLAPISAN TANAH}

Dari boring log yang ada dapat di klasifikasi perlapisan tanah adalah sebagai berikut :
Tabel 1: Klasifikasi Perlapisan Tanah

\begin{tabular}{|c|c|c|c|}
$\begin{array}{c}\text { Depth } \\
(\mathrm{m})\end{array}$ & $\begin{array}{c}\text { Consistency/ } \\
\text { Relative } \\
\text { Density }\end{array}$ & $\begin{array}{c}\text { N SPT } \\
\text { (Average) } \\
\text { (Blows) }\end{array}$ & $\begin{array}{c}\text { N SPT } \\
\text { (Design) } \\
\text { (Blows) }\end{array}$ \\
\hline $0-11$ & $\begin{array}{c}\text { Relative } \\
\text { Density }\end{array}$ & $5-10$ & 7 \\
\hline $11-20$ & $\begin{array}{c}\text { Medium } \\
\text { Stiff }\end{array}$ & $8-15$ & 12 \\
\hline $20-30$ & $\begin{array}{c}\text { Medium } \\
\text { Dense }\end{array}$ & $22->50$ & 22 \\
\hline
\end{tabular}

Dari nilai-nilai korelasi diatas terdapat nilai N SPT Design yang akan digunakan untuk kepentingan desain potensi liquifaksi, kapisitas daya-dukung aksial dan lateral. 


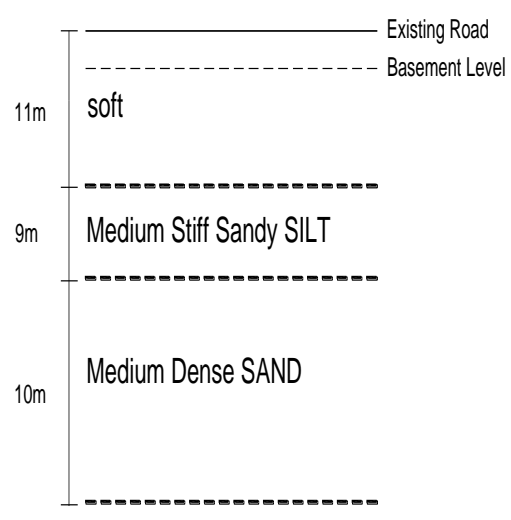

menjadi dasar dalam perencanaan sistim pondasi dalam tiang pancang.

\section{POTENSI LIQUIFAKSI}

Analisa tentang potensi likuifaksi adalah salah satu bagian terpenting yaitu karena dari struktur tanah yang dominan pasir dan lanau serta memiliki relative density atau konsistensi yang cenderung loose atau soft serta kemungkinan muka air tanah yang cukup tinggi.

Gambar 1: Profil Perlapisan Tanah

Gambar diatas adalah profil perlapisan tanah beserta dengan konsistensinya yang akan

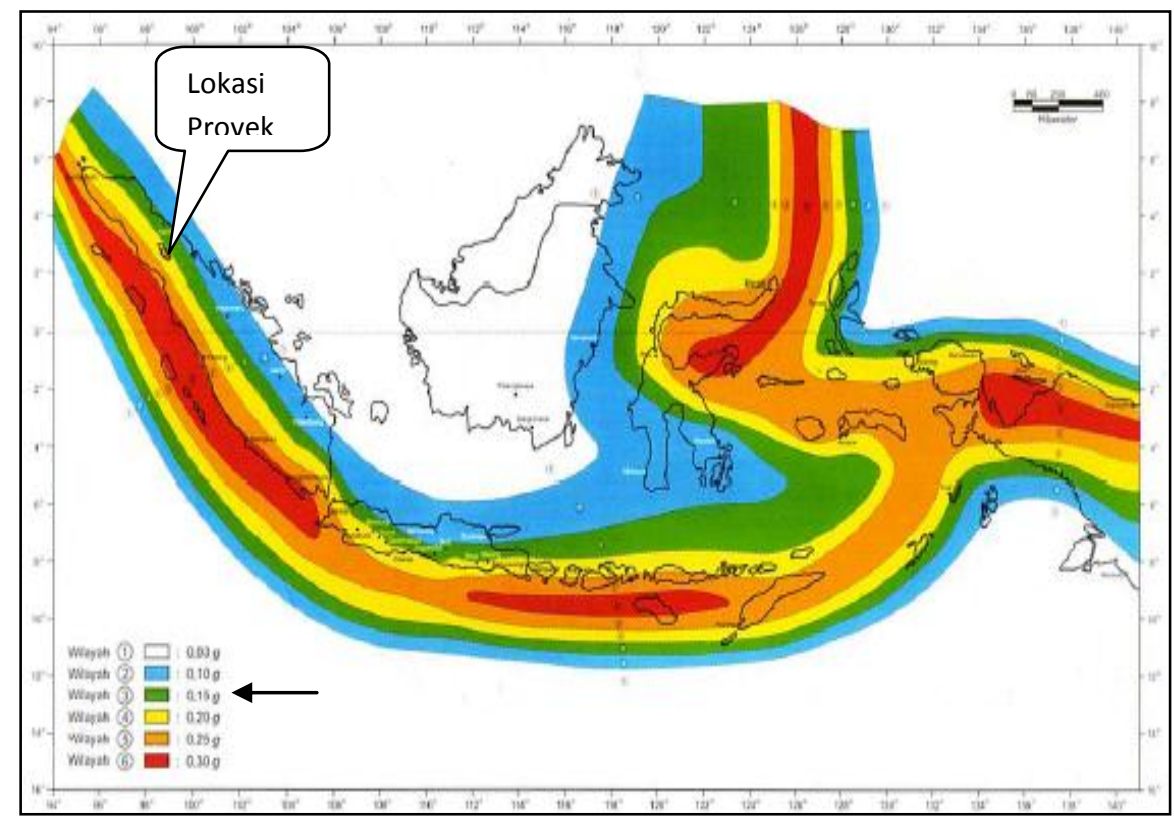

Gambar 2: Peta Gempa di Indonesia

Dari PETA GEMPA 2002 diatas disimpulkan bahwa kota Medan memiliki PGA pada base rock $\mathbf{a}_{\max }=\mathbf{0 . 1 5 g}$, Rencana Besaran (Magnitude) gempa adalah skala $\underline{\mathbf{6 . 5}}$. 


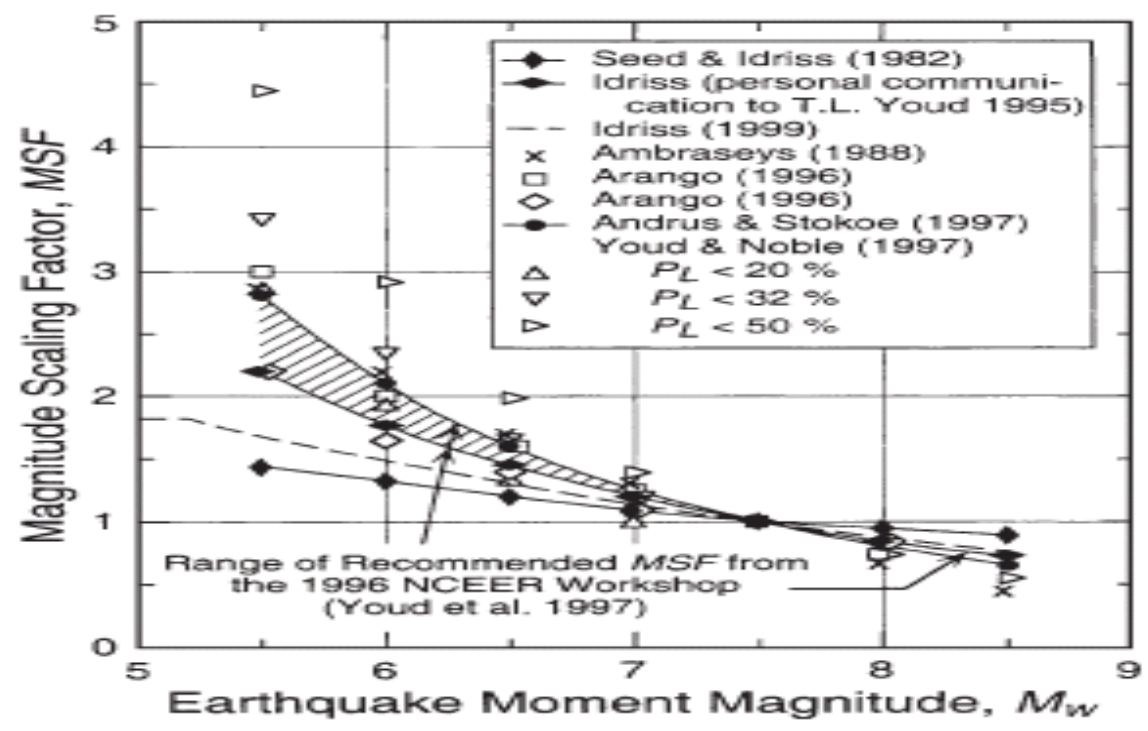

Gambar 3: Grafik Magnitute Scalling Factor

Gambar diatas menyimpulkan bahwa MSF (Magnitute Scalling Factor) untuk skala 6.5 adalah 1.5. Dari data profil perlapisan disimpulkan bahwa jenis tanah pada daerah proyek adalah tanah lunak atau soft soil.

Tabel 2 : Amplification Factor Untuk Tanah Lunak

\begin{tabular}{|c|c|c|c|}
\hline $\mathrm{e}$ & $\begin{array}{c}\text { Percepatan } \\
\text { Puncak } \\
\text { Batuan } \\
\text { Dasar (g) }\end{array}$ & $\begin{array}{c}\text { Faktor } \\
\text { Amplifik } \\
\text { asi } \\
\text { untuk } \\
\text { Soft Soil }\end{array}$ & $\begin{array}{c}\text { Percepatan } \\
\text { Puncak Batuan } \\
\text { Dasar untuk } \\
\text { Soft Soil (g) }\end{array}$ \\
\hline 1 & 0.03 & 2.67 & 0.08 \\
\hline 2 & 0.10 & 2.00 & 0.20 \\
\hline 3 & 0.15 & 2.00 & 0.30 \\
\hline 4 & 0.20 & 1.70 & 0.34 \\
\hline 5 & 0.25 & 1.44 & 0.36 \\
\hline 6 & 0.30 & 1.27 & 0.38 \\
\hline
\end{tabular}

Tabel diatas adalah tabel amplification factor untuk tanah lunak dari SNI 2002 yang berarti bahwa PGA pada permukaan tanah pada daerah proyek adalah $\mathrm{a}_{\max }=0.3$

Metode yang akan dipakai untuk menganalisa potensi likuifaksi adalah metode sederhana atau simplified empirical methods dengan data N SPT atau CPT. Metode ini terdiri dari langkah-langkah sebagai berikut :

1. Mencari CSR, Cyclic Stress Ratio yang disebakan oleh gempa.

2. Mencari CRR, Cyclic Resistance Ratio dari data N SPT atau CPT.

3. Menghitung $\mathrm{FK}=\frac{C R R}{C S R}$, dimana jika $\mathrm{FK}<$ 1 maka likuifaksi bisa terjadi dan jika $\underline{\text { FK }}$ $>1$ likuifaksi tidak terjadi.

Formula dan grafik untuk parameter-parameter diatas adalah :

$$
\operatorname{CSR}=\frac{\tau_{\mathrm{cyc}}}{\sigma_{v 0}^{\prime}}=0.65 r_{d}\left(\frac{\sigma_{v 0}}{\sigma_{v 0}^{\prime}}\right)\left(\frac{a_{\max }}{g}\right)
$$

$$
r_{d}=1-0.012 z
$$

Dimana :

$$
\begin{array}{ll}
\mathrm{a}_{\max }= & \begin{array}{l}
\text { Percepatan Puncak Batuan pada } \\
\text { permukaan tanah }(\mathrm{g})
\end{array} \\
\mathrm{g} & =\text { Percepatan gravitas }(\approx 1000 \mathrm{~g}) \\
\sigma_{\mathrm{vo}} & =\text { Tegangan vertical total }(\mathrm{kPa}) \\
\sigma_{\mathrm{vo}} & =\text { Tegangan vertical efektif }(\mathrm{kPa}) \\
\mathrm{r}_{\mathrm{d}} & =\text { Faktor reduksi }
\end{array}
$$




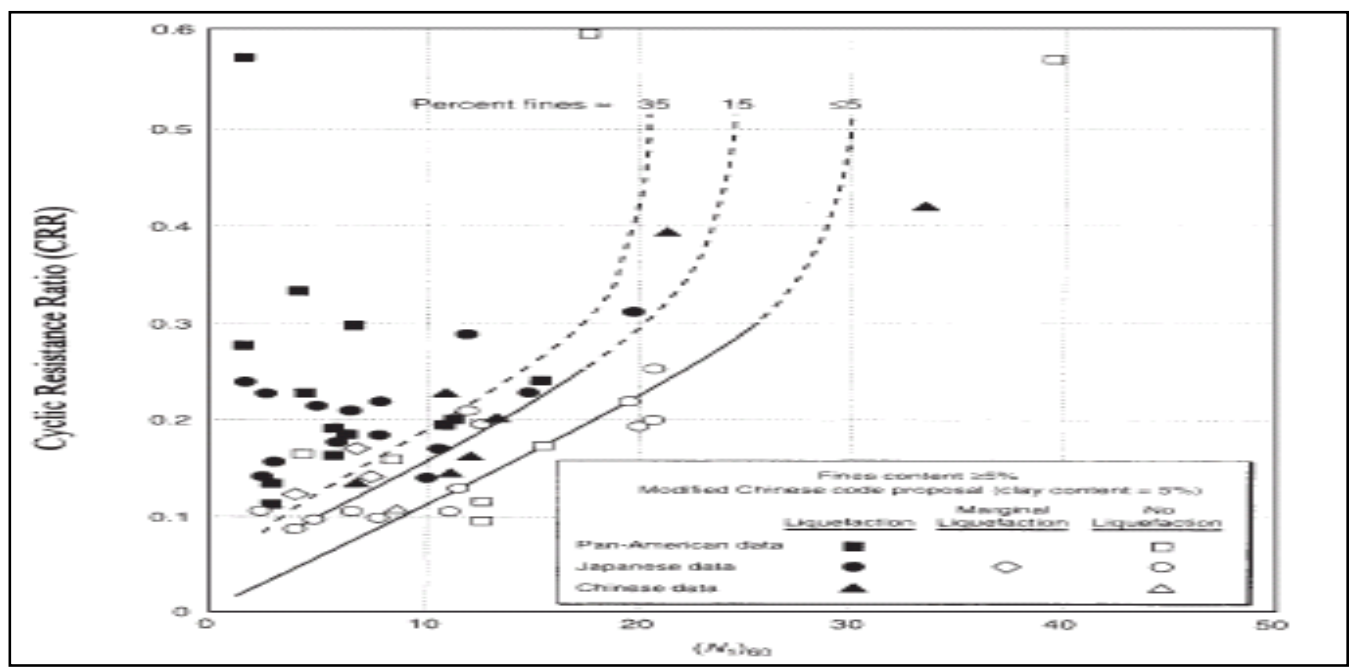

Gambar 4: Grafik Cyclic Resistence Rasio

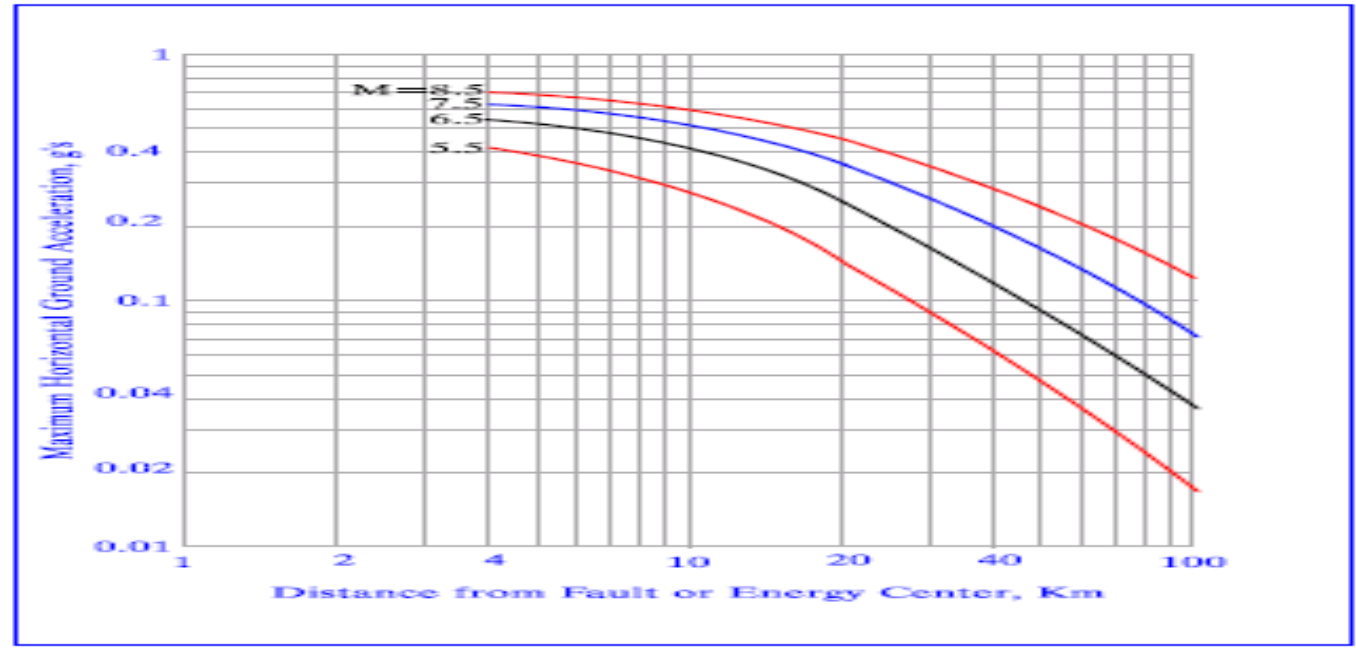

Gambar 5: Grafik Maximum Horizontal Ground Acseleration

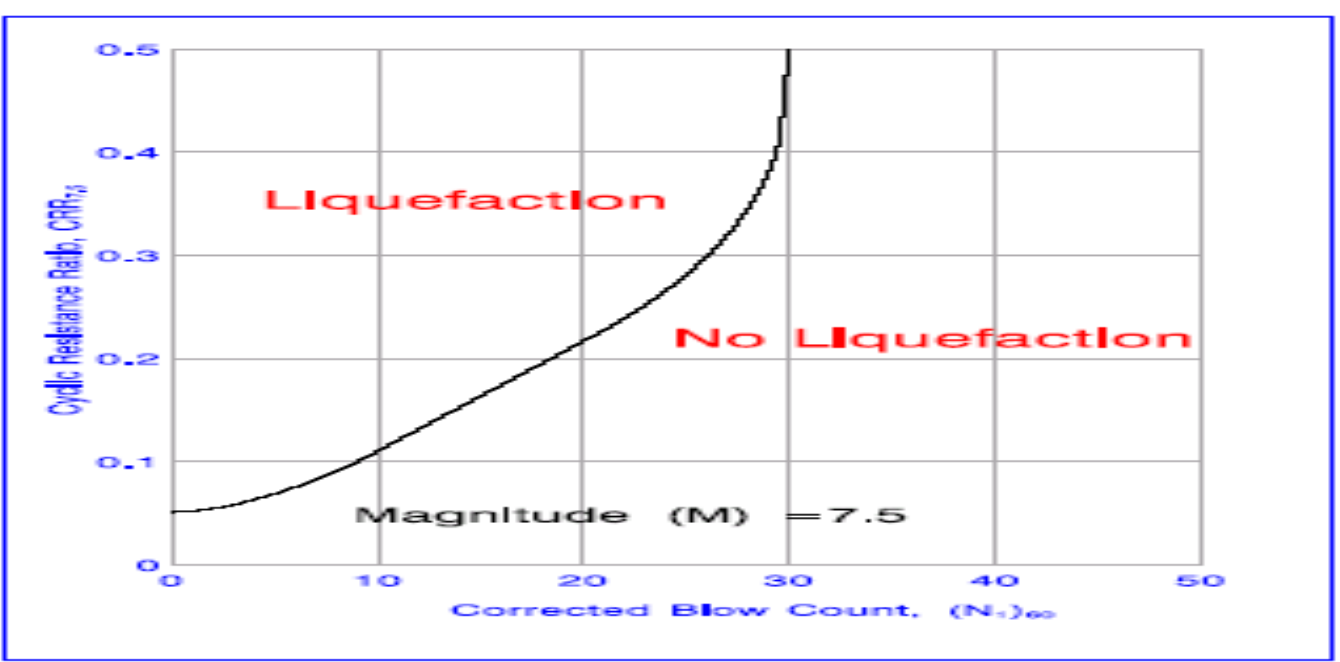

Gambar 6: Hubungan Grafik Cyclic Resistence Rasio \& Corrected Blow Count

Computer Science | Industrial Engineering | Mechanic Engineering | Civil Engineering 
Dari grafik-grafik diatas ditabulasi perhitungan FK terhadap potensi likuifaksi adalah sebagai berikut :

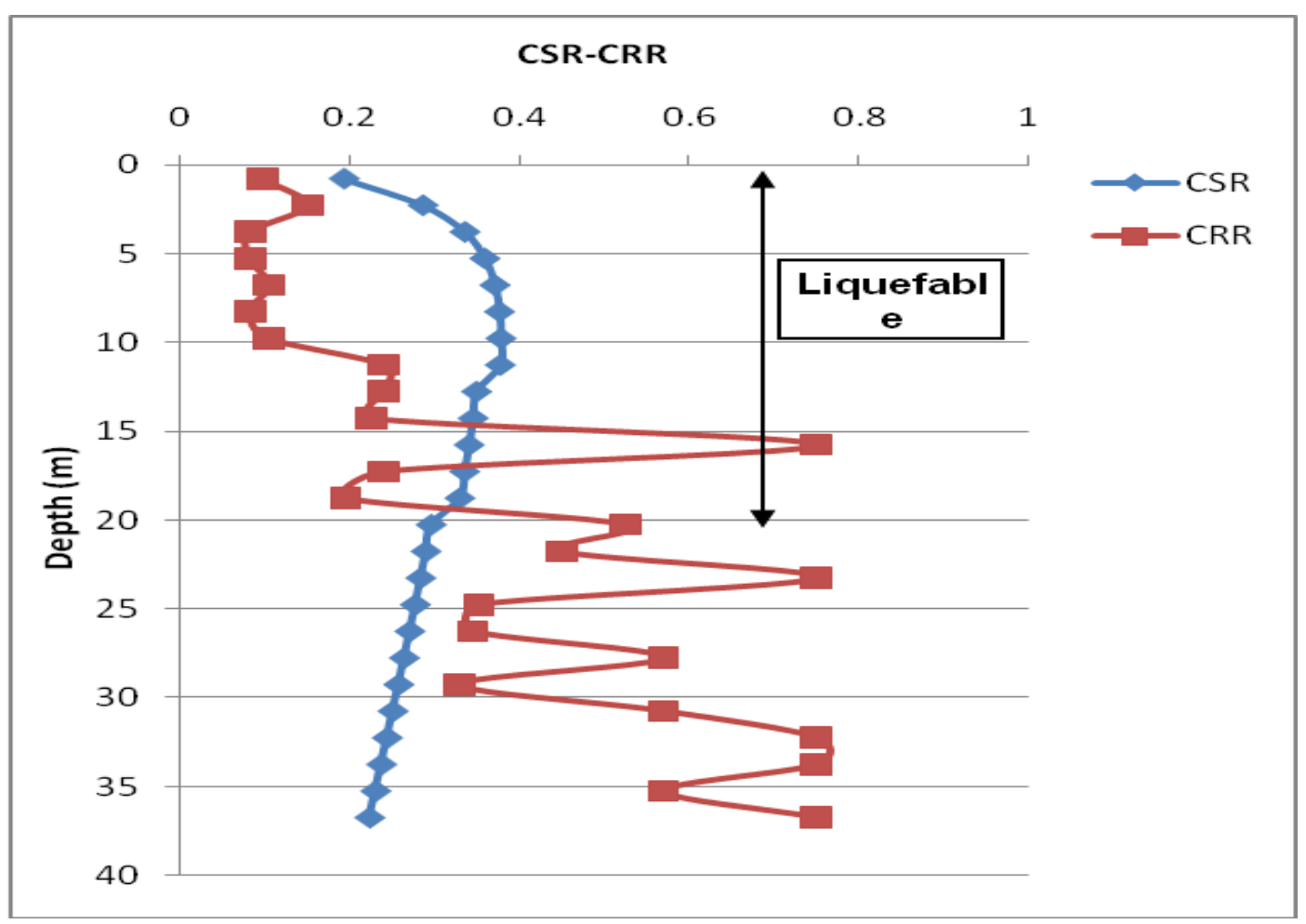

Gambar: 7 Grafik Dept dan CSR-CRR

Dari tabel dan grafik diatas dapat disimpulkan bahwa potensi likuifaksi untuk desain gempa skala 6.5 adalah sedalam zone potensi likuifakasi yaitu $\underline{\mathbf{0 - 2 0 m}}$.

\section{ANALISA}

\section{A. KAPASITAS DUKUNG AKSIAL}

Kapasitas dukung aksial tiang pancang akan dihitung secara manual dengan metode Schmertmann (1967) yaitu dengan menggunakan nilai N SPT untuk disain static maupun disain gempa-likuifaksi. Tiang pancang yang akan dipakain yaitu tiang pancang spun pile dengan $\mathbf{L}=\mathbf{2 5} \mathrm{m}$ dan diameter $\mathbf{5 0} \mathrm{cm}$.
Metode Schmertman menetapkan untuk pasir bersih Gesekan Selimut $=0.019 \times$ NSPT dan Tahanan Ujung $=3.2 \times \mathrm{N}-\mathrm{SPT}$.

Sedangkan untuk pasir kelanauan atau lanau kepasiran Gesekan Selimut $=0.04 \mathrm{x}$ NSPT dan Tahanan Ujung $=1.6 \times$ N-SPT dan tipikal profil perlapisan tanah seperti gambar dibawah : 


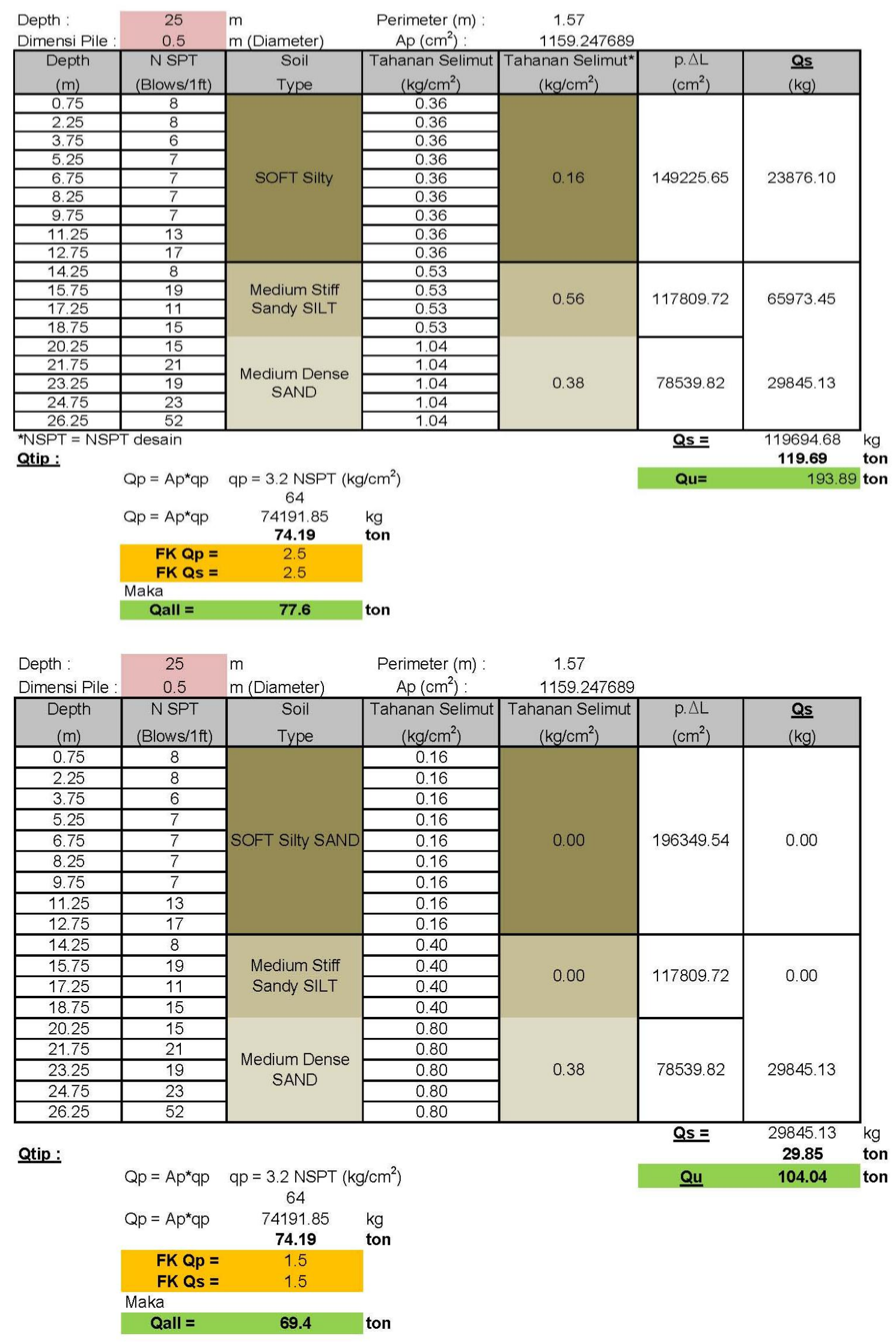

Computer Science | Industrial Engineering | Mechanic Engineering | Civil Engineering 


\section{B. PASITAS DUKUNG LATERAL}

Kapasitas daya dukung lateral akan didekati dengan 3 metode yaitu (1) Dengan menggunakan metode Broms (2) Dengan menggunakan Metode Elemen Hingga dan (3) Dengan menggunakan Software LPILE (Com624).

\section{METODE BROMS}

Metode yang menggunakan diagram tegangan tanah dengan menganggap bahwa sepangjang kedalaman tiang, reaksi atau tahanan tanah mencapai ultimate. Telebih dahulu mencari $\mathrm{T}$ (diketahui $\eta_{\mathrm{h}}$ ) untuk mendeskripsikan apakah tiang berprilaku tiang pendek atau tiang panjang.

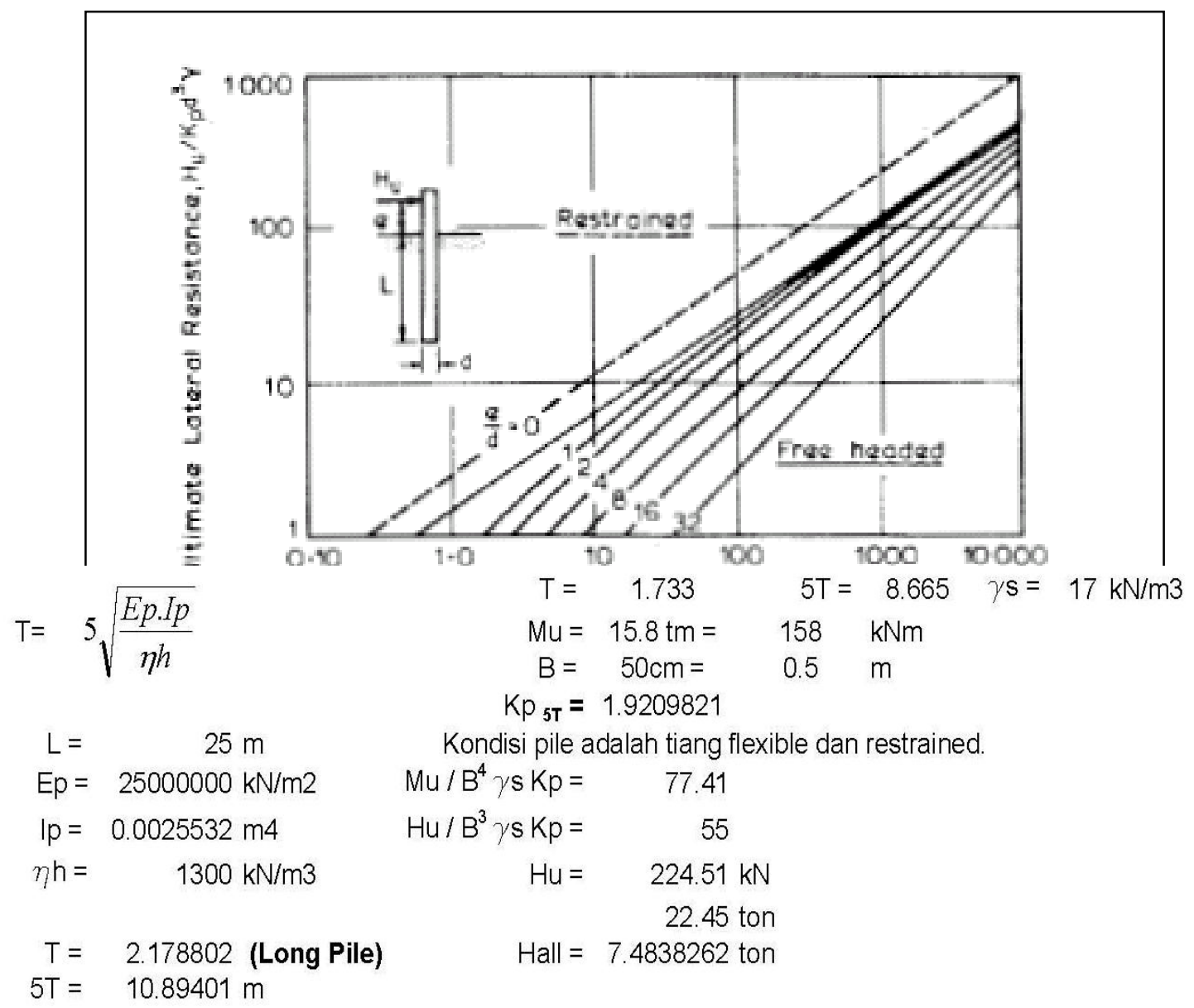

\section{METODE ELEMEN HINGGA}

Tiang pancang dibagi menjadi 4 elemen dengan panjang (L) yang berbeda namun
Elastisitas (Ep) dan Ip adalah sama. Gambar diatas adalah finite element dari tiang pancang sedalam $25 \mathrm{~m}$. 


\begin{tabular}{|lc|}
\hline \multicolumn{2}{|l|}{ Range of modulus of subgrade } \\
reaction $\boldsymbol{k}_{\boldsymbol{s}}$ \\
$\begin{array}{l}\text { Use values as guide and for comparison when } \\
\text { using approximate equations }\end{array}$ \\
\hline Soil & $\boldsymbol{k}_{s}, \mathbf{k N} / \mathrm{m}^{3}$ \\
\hline Loose sand & $4800-16000$ \\
Medium dense sand & $9600-80000$ \\
Dense sand & $64000-128000$ \\
Clayey medium dense sand & $32000-80000$ \\
Silty medium dense sand & $24000-48000$ \\
Clayey soil: & $12000-24000$ \\
$q_{a} \leq 200 \mathrm{kPa}$ & $24000-48000$ \\
$200<q_{a} \leq 800 \mathrm{kPa}$ & $>48000$ \\
$q_{a}>800 \mathrm{kPa}$ & \\
\hline
\end{tabular}

Tabel 3: Range Og Modulus Of Subgrade

Dua hal yang penting dalam metode elemen hingga pada kasus ini yaitu :

1. Matrix kekakuan balok $\left[\mathrm{K}_{\mathrm{T}}\right]$

2. Matrix kekakuan Tanah $\left[K_{F}\right]$
Dimana tanah dianggap memiliki kekakuan pegas yang diambil dalam parameter Ks atau modulus of subragde reaction (Seperti pada tabel-tabel diatas).

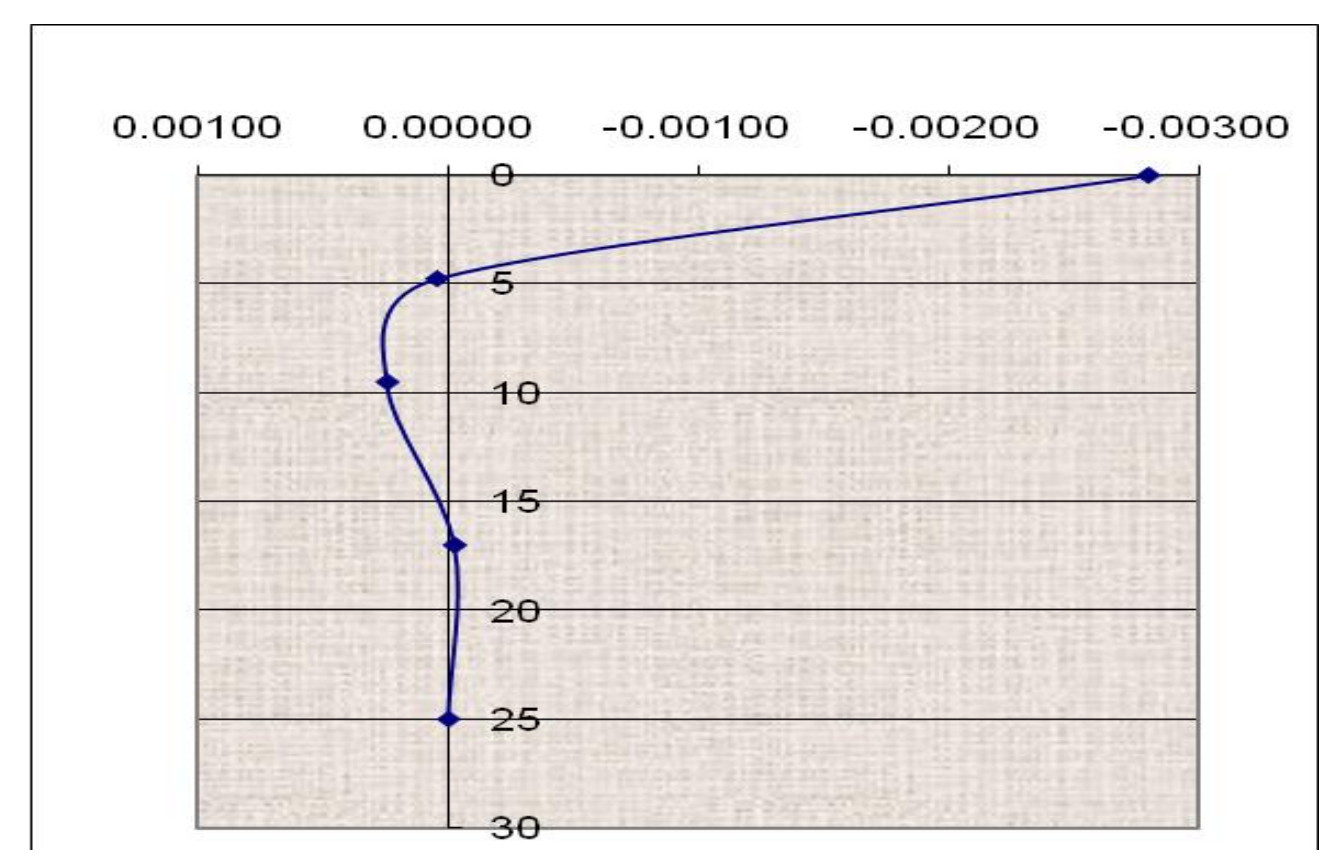

C. DAYA DUKUNG LATERAL (LPILE)

Computer Science | Industrial Engineering | Mechanic Engineering | Civil Engineering 
Program computer LPile dari Ensoft dipakai untuk menghitung kapasitas lateral pada kondisi statik. Pada kondisi statik kurva p-y yang dipakai adalah kurva p-y alami berdasarkan undrained soil strength.

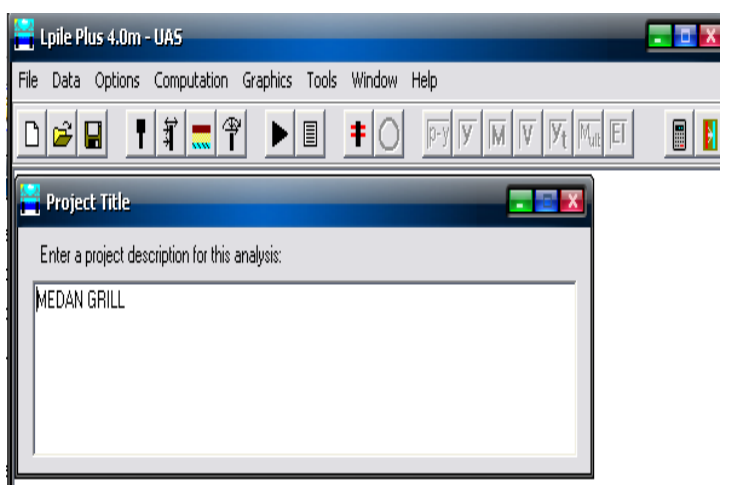

Gambar 8: Laman Awal Program LPile

\begin{tabular}{|c|c|}
\hline Pile Properties & \\
\hline Total Eile Length (m) & 25 \\
\hline Number of !ncrements & 100 \\
\hline $\begin{array}{l}\text { Distance from Pile Top to Ground Surface (m) } \\
\text { (negative if pile top is below ground) }\end{array}$ & 0 \\
\hline Combined Ground Slope and Batter Angles (degrees) & 0 \\
\hline Edit Pile Sectional Properties & \\
\hline
\end{tabular}

Gambar 9: Laman Pile Properties

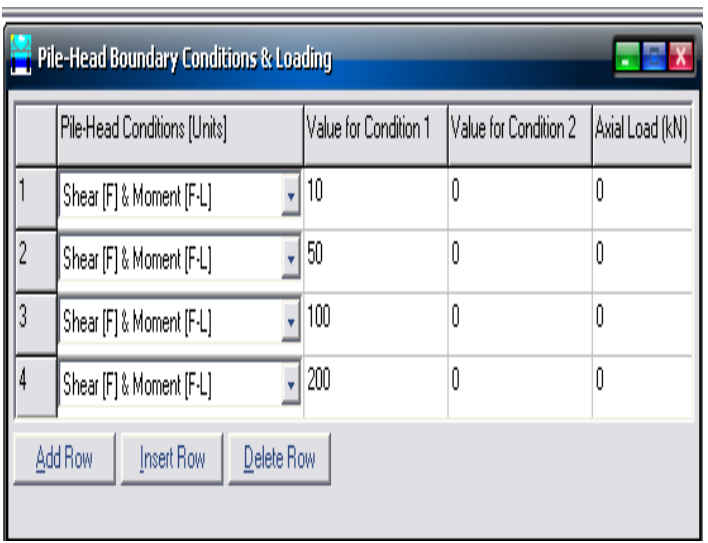

Gambar 10: Laman Head Boundary Condition

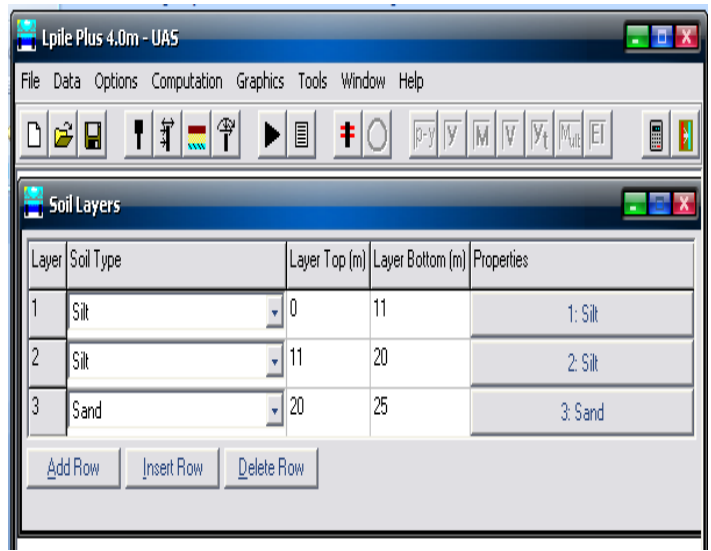

Gambar 11: Pemilihan Jenis Tanah

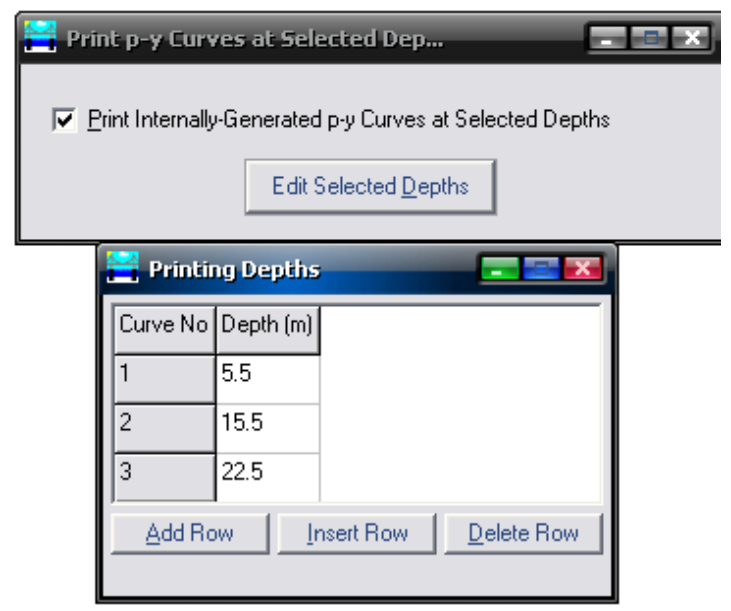

Gambar 12: Cetak Kurva Hasil Pemilihan Tanah 

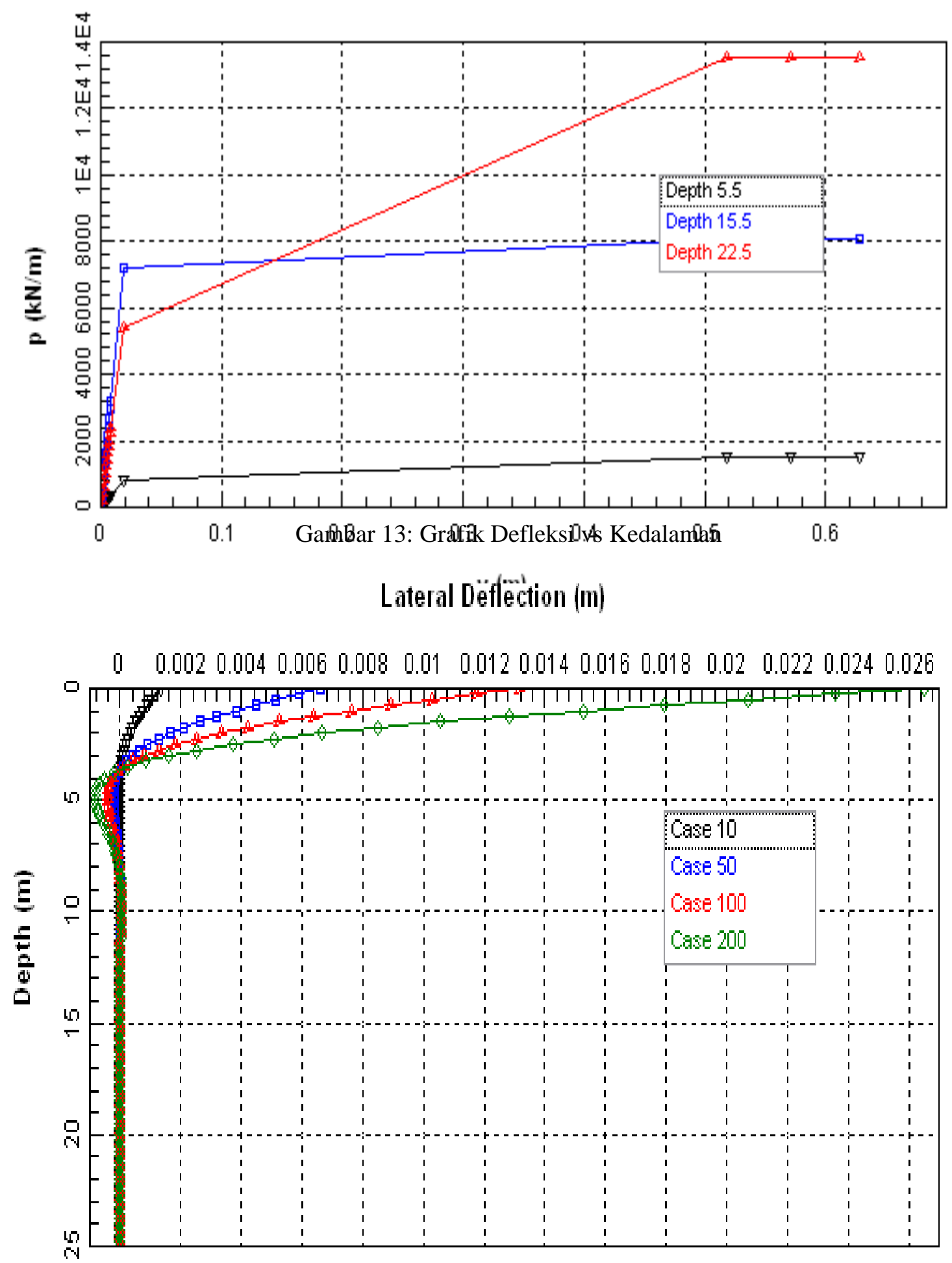

Gambar 14: Grafik Defleksi vs Beban Latera

Gambar Defleksi vs Kedalaman dan Defleksi vs Beban Lateral yang diberikan, bila defleksi ijin pada kondisi $1 / 4$ inch atau $0.64 \mathrm{~cm}$ maka beban lateral ijin statik adalah 3.5 ton dan untuk beban lateral ijin kondisi p-y cyclic adalah 7.5 ton

Computer Science | Industrial Engineering | Mechanic Engineering | Civil Engineering 


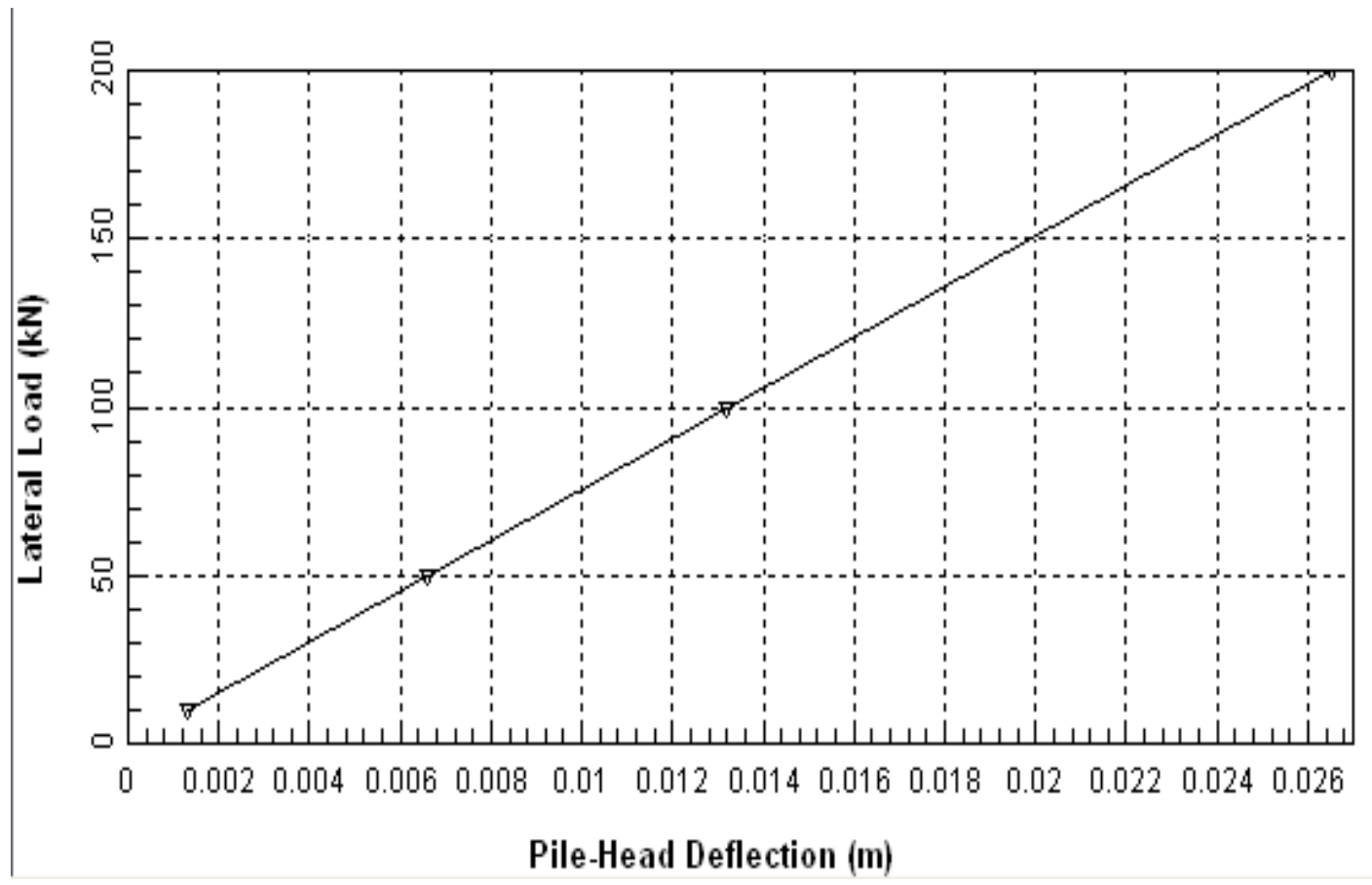

Gambar 15: Grafik Lateral Load vs Pile-Head Deflection

\section{KESIMPULAN}

Profil perlapisan tanah dapat dibagi ke dalam 3 kategori : Pada BH 07:

1. Pasir kelanauan $(0-11 \mathrm{~m})$ dengan kepadatan relatif yang Soft.

2. Lanau kepasiran (11-20m) dengan konsistensi medium stiff.

3. Pasir (20-30m) dengan kepadatan relatif yang medium dense.

Kapasitas daya dukung ultimate $(\mathrm{Qu})$ dan allowable lateral( $\mathrm{H}$ al $) 1$ telah dianalisa dengan metode Broms, metode Elemen Hingga (FEM) dan dengan bantuan program computer LPILE (Com624). Dari perhitungan-perhitungan diatas dapat disimpulkan :

1. Metode Broms : Kapasitas daya dukung lateral ultimate adalah 22.45 ton, $\mathrm{FK}=3$ maka kapasitas lateral ijin adalah 7.5ton (Broms).
2. LPILE : Defleksi ijin pada kondisi $1 / 4$ inch atau $0.64 \mathrm{~cm}$ maka beban lateral ijin statik adalah 3.5 ton dan untuk beban lateral ijin kondisi p-y cyclic adalah 6.5 ton.

\section{DAFTAR PUSTAKA}

Arifin, Zainul , 2010. "Komparasi Daya DUkung Aksial Tiang Tunggal Dihitung Dengan Beberapa Metode Analisis", Tesis fakultas teknik Universitas Diponegoro Semarang .

Iskandar, Rudi. 2002. "Beberapa Kendala Teori Perhitungan Daya Dukung Aksial Pondasi Dalam", USU, Sumatra Utara.

Das, Braja, M, 1995, Mekanika Tanah 1, Penerbit ERLANGGA, Jakarta.

Das, Braja, M, 2006, Principles of Geotechnical Engineering fourth edition, KENT Publishing Company, Boston. 
Das, Braja, M, 2006, Principles of Geotechnical Engineering fifth edition, Thomson Canada Limited, Canada.

Das, Braja, M, 2006, Principles of Geotechnical Engineering seventh edition, California State University, Sacramento.

Tomlinson, M.J., 1997, Pile Design and Construction Practice, 1st Edition, View Point Publishing, London.

Tomlinson, Michael, 2008, Pile Design and Construction Practice fifth edition, Taylor \& Francis e-Library, New York.

Bowles, Joseph.E.,1997, "Foundation Analysis and Design", McGraw-Hill Companies,Inc., Illinois

Sardjono,HS, 1988, Pondasi Tiang Pancang, Jilid 1, Penerbit SINAR JAYA WIJAYA, Surabaya.

Sardjono, H.S, 1998, Pondasi Tiang Pancang, Jilid 2, Penerbit SINAR JAYA WIJAYA, Surabaya.

Sosrodarsono, S. Dan Nakazawa, K, 1983, Mekanika Tanah dan Teknik Pondasi, PT Pradaya Paramita, Jakarta.

Bowles, J. E, 1991, Analisa dan Desain Pondasi, Edisi keempat Jilid 1, Erlangga, Jakarta.

Bowles, J. E, 1993, Analisa dan Desain Pondasi, Edisi keempat Jilid 1, Erlangga, Jakarta.

Hardiyatmo, H, C., 2002, Teknik Pondasi 2, Edisi Kedua, Beta Offset, Yogyakarta 